Environmental Management

Elsevier Editorial System(tm) for Journal of

Manuscript Draft

Manuscript Number: JEMA-D-18-00610R2

Title: Applying organization science to assess the management performance of Marine Protected Areas: an exploratory study

Article Type: Research Article

Keywords: Mediterranean MPA, organizational features, performance assessment, performance index

Corresponding Author: Dr. Claudia Scianna, Ph.D.

Corresponding Author's Institution:

First Author: Claudia Scianna, Ph.D.

Order of Authors: Claudia Scianna, Ph.D.; Federico Niccolini, Prof; Carlo Nike Bianchi, Prof; Paolo Guidetti, Prof

Abstract: Marine Protected Areas (MPAs) are important tools to achieve marine conservation and resources management goals. The management effectiveness of MPAs (the degree to which MPAs achieve their goals) is highly variable and can be affected by many MPA attributes, for example their design, enforcement and age. Another key factor possibly affecting MPA management effectiveness is the management performance, here conceived according to Horigue et al. definition (2014) as the "level of effort exerted to enhance and sustain management of MPAs". Organization Science (OS), the discipline that studies organizations, can offer a useful framework to assess and interpret MPA management performance. Using an exploratory multiple case study approach, we applied os principles to 11 Mediterranean MPAs in order to: i) characterize several MPA organizational features; ii) assess MPA management performance (evaluated as the effort deployed in, for example, planning the future, formalizing measurable goals and implementing specific strategies). Results show that a number of organizational features and networking attributes are highly variable among the MPAs we have studied. For instance, goals are seldom measurable and the strategy to achieve goals is not systematically pursued. Two relevant outcomes emerge from this exploratory study: i) the management performance of the MPAs considered needs considerable improvements; ii) the methods and the approach proposed could help MPAs' managers and policy makers to understand how to improve their management performance and, consequently, their effectiveness. 


\section{Applying organization science to assess the management performance of Marine Protected Areas: an exploratory study}

Claudia Scianna $^{\mathrm{a} * \S}$, Federico Niccolini $^{\mathrm{b}}$, Carlo Nike Bianchi ${ }^{\mathrm{c}}$, Paolo Guidetti ${ }^{\mathrm{a}, \mathrm{d}}$

a Université Côte d'Azur, CNRS, FRE 3729 ECOMERS, Parc Valrose 28, Avenue Valrose, 06108 Nice, France

${ }^{\mathrm{b}}$ Department of Economy and Management, University of Pisa, via C. Ridolfi 10, 56124 Pisa, Italy

${ }^{c}$ DiSTAV, Department of Earth, Environment and Life Sciences, University of Genoa, Corso Europa 26, 16132 Genoa, Italy

${ }^{\mathrm{d}}$ Interuniversity Consortium of Marine Sciences (CoNISMa), Piazzale Flaminio 9, 00196 Rome, Italy

* Corresponding author. Université Côte d'Azur, CNRS, FRE 3729 ECOMERS, Parc Valrose 28, Avenue Valrose, 06108 Nice, France. Email address:claudia.scianna@ unice.fr

$\S$ Present address: WWF Italy, Via Po 25/C, 00198, Rome, Italy. 
1

\section{Abstract}

2 Marine Protected Areas (MPAs) are important tools to achieve marine conservation and 3 resources management goals. The management effectiveness of MPAs (the degree to which 4 MPAs achieve their goals) is highly variable and can be affected by many MPA attributes, for 5 example their design, enforcement and age. Another key factor possibly affecting MPA 6 management effectiveness is the management performance, here conceived according to Horigue 7 et al. definition (2014) as the "level of effort exerted to enhance and sustain management of 8 MPAs". Organization Science (OS), the discipline that studies organizations, can offer a useful 9 framework to assess and interpret MPA management performance. Using an exploratory 10 multiple case study approach, we applied OS principles to 11 Mediterranean MPAs in order to: i) 11 characterize several MPA organizational features; ii) assess MPA management performance 12 (evaluated as the effort deployed in, for example, planning the future, formalizing measurable 13 goals and implementing specific strategies). Results show that a number of organizational 14 features and networking attributes are highly variable among the MPAs we have studied. For 15 instance, goals are seldom measurable and the strategy to achieve goals is not systematically 16 pursued. Two relevant outcomes emerge from this exploratory study: i) the management 17 performance of the MPAs considered needs considerable improvements; ii) the methods and the 18 approach proposed could help MPAs' managers and policy makers to understand how to 19 improve their management performance and, consequently, their effectiveness.

\section{Key words}

23 Mediterranean MPA, organizational features, performance assessment, performance index 24 


\section{Introduction}

Protected areas (PAs) are usually defined as "clearly defined geographical spaces, 30 recognized, dedicated and managed, through legal or other effective means, to achieve the long31 term conservation of nature with associated ecosystem services and cultural values" (Dudley, 32 2008). Marine protected areas (MPAs) share the same characteristics with PAs (which they are 33 part of) but are specifically dedicated to marine ecosystems. Following the IUCN classification, 34 MPAs fall into different PA categories on the basis of the objectives they have been created for 35 (Day et al., 2012). MPAs are generally considered as important tools to achieve marine 36 conservation and/or resources management goals (Gaines et al., 2010; Parravicini et al., 2013).

Management effectiveness is the success or the degree to which MPAs achieve their goals (Hockings et al., 2006) and it has been proved to be highly variable (Lester et al., 2009). Management effectiveness can be affected by many MPA attributes (e.g. design, age) along with a number of ecological features, social behaviour and land-based pressures (e.g., species characteristics, habitat continuity, compliance, outfalls) (Claudet et al., 2008; Edgar et al., 2014; Guidetti et al., 2014; Lester et al., 2009; McClanahan et al., 2006).

MPA management effectiveness can be also affected by the 'management performance', defined by Horigue et al. (2014) as "the level of effort exerted to enhance and sustain management of MPAs". In other words, management performance is what managers and decision makers do in order to improve the degree of achievement of MPA goals. Such a definition of management performance formally distinguishes between the concepts of "effectiveness" and "performance", which have been considered as synonymous in the past (Ervin, 2003; Jones, 2014; Pomeroy et al., 2004; Tempesta \& Otero, 2013) and still are in some studies (Ban et al., 2017; Emslie et al., 2015; Gill et al., 2017). Only few studies have dealt so far with management performance according to the previous definition and employing specific approaches and tools to investigate it (Horigue et al., 2014; Rodríguez-Rodríguez et al., 2016).

Several tools for the assessment of MPA management processes have been already developed (Leverington et al., 2010), such as the Management Effectiveness Tracking Tool (METT) (Stolton et al., 2007), World Bank MPA Score Card (Staub \& Hatziolos, 2004), and 

Rapid Assessment and Prioritization of Protected Area Management Methodology (RAPPAM) (Ervin, 2003). These tools mainly involve data collection through expert opinions and the Likert scale. The aim of this study is to develop a novel and science-based approach to help policy makers and managers take into consideration organizational features to assess and compare MPA's performance, without however creating an organic and holistic Management Performance System (Anthony \& Govindarajan, 1998). Consistently with the performance definition of Horigue et al. (2014), assessing MPA performance is here considered as a fundamental step towards gauging MPA effectiveness.

MPAs are organizations (Scianna et al., 2015) and consequently their management features and performance can be analyzed by applying the Organization Science (OS) approach. OS is a discipline that studies the structures, processes and practices of organizations, and offers useful tools to identify the interventions needed to benefit the organization themselves (Daft, 2010). In OS, organizations are defined as "cooperative systems of consciously coordinated activities of two or more persons, with a common purpose" (Barnard, 1938). MPAs are entities where people, at different hierarchical levels, cooperate to carry out activities, such as enforcement, environmental education and monitoring of socio-ecological variables, in order to pursue one or more well-defined common objectives (e.g. conservation of specific species, restoration of fish stocks).

OS principles and methods have been conceived to study the traits of different public and non-profit organizations, such as schools, federal or governmental agencies and NGOs (Bryson, 1988; Daft, 2010; Ingersoll, 2001; Rainey \& Steinbauer, 1999). The lessons learnt from OS research may therefore have broad relevance for the analysis of MPAs and their management performance.

Each organization is characterized by its dimensions, specific design traits that allow for comparisons (Daft, 2010). The organizational dimensions delineate the organization's structure (Pugh et al., 1968), such as the workforce on which the MPA can rely, defined as the 'organizational size'. It is important to clarify that herein MPA size does not refer to the surface area of the MPA as is often the case in MPA-relevant literature (e.g. Claudet et al., 2008; Lester et al., 2009; Sala et al., 2012), but to the workforce in an MPA. The organizational dimensions describe also the context of an organization and define why it exists (mission), where it wants to go (vision), what it wants to achieve (goals) and how (strategy). Within this framework, vision 
87 and mission are part of the culture (the shared fundamental values) of the organization, and, 88 together with the analysis of the strategy and the related activities, they can be taken into account 89 in the assessment of MPA management performance (Fig. 1, see section 2 for more details). 90 Management monitoring can provide hints to readjust the entire management process. The 91 assessment of the management performance could allow rearrangement of the strategy, which, in 92 turn, may improve the management performance itself. Management effectiveness should then 93 be assessed as the degree of achievement of the goals. The assessment of the management 94 effectiveness could provide a basis for identification of the steps of the management process that 95 do not enable the achievement of their goals (if this is the case), and consequently their revision 96 and restatement.

The present work is an exploratory study aiming at: i) applying for the first time, to our knowledge, the OS approach to the MPA context, introducing new concepts together with their definitions, ii) developing new and standardized methods based on factual data (and not on expert opinion), collected through a questionnaire and summed up through new indices, iii) evaluating a number of Mediterranean MPAs from an organizational point of view, characterizing their legal status and authority, several organizational features and their management performance.

Fig. 1. Conceptual flow diagram of the management monitoring. Links between some organizational dimensions and (the assessment of) management performance and effectiveness. Management effectiveness and related arrows are in light grey because they are beyond the scope of the present study. 


\subsection{Study areas}

We firstly contacted via e-mail 15 MPA management bodies selected in the 112 Mediterranean Sea among those that actively manage MPAs through legal means (following the 113 IUCN PA definition) (Dudley, 2008). We sent three follow-up emails before considering an 114 MPA as not responsive. The management bodies related to eleven MPAs responded to our 115 invitation to take part in this study, representing a response rate of $\sim 73 \%$. These MPAs are 116 located in 4 Mediterranean countries, i.e. France, Greece, Italy and Spain (Table 1, Fig. 2). These 117 countries host about $75 \%$ (in terms of surface, i.e. $14059 \mathrm{~km}^{2}$ out of $18967.55 \mathrm{~km}^{2}$ ) of all MPAs 118 established in the Mediterranean Sea (Gabrié et al., 2012), representing the states that deploy 119 more effort in using the MPAs as tools to actively conserve their marine ecosystems. The 120 possibility of getting organizational data strictly depends, for each MPA, on the existence of a 121

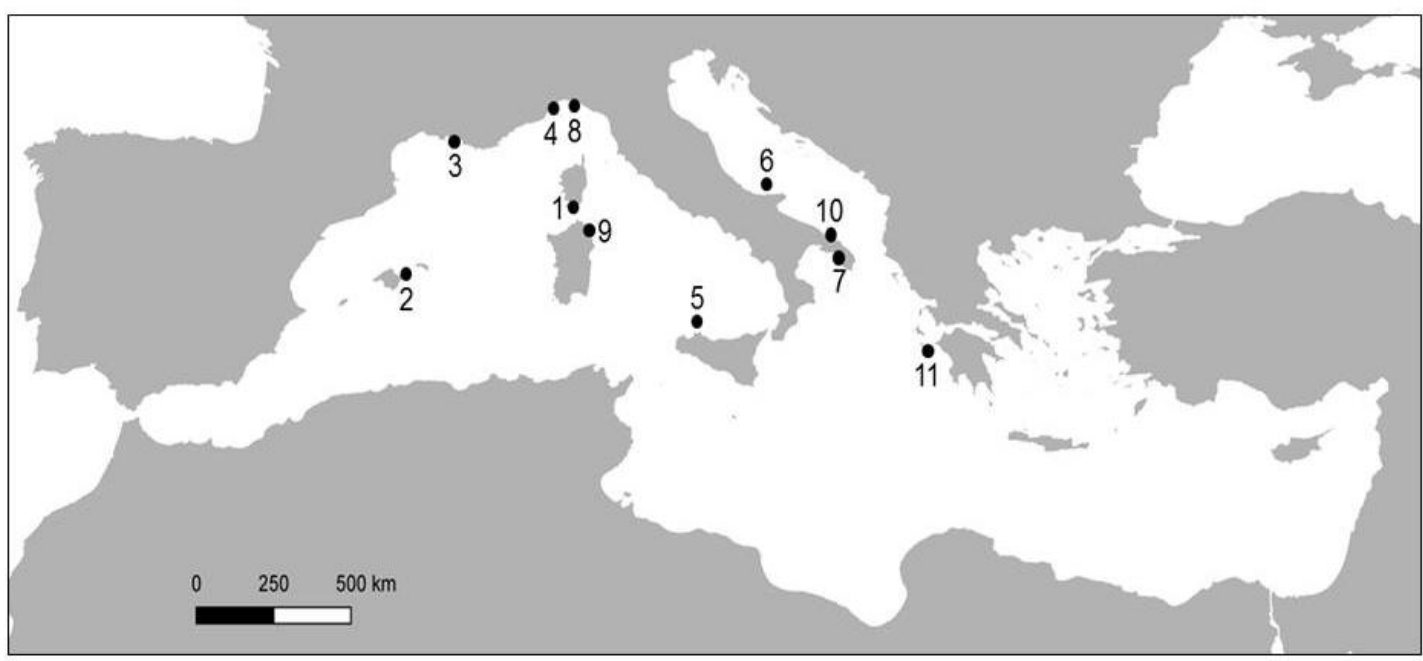

Fig. 2. Geographical location of the 11 MPAs investigated. 1) Bouches de Bonifacio Natural Reserve, 2) Cala Ratjada-Peninsula de Llevante Marine Reserve, 3) Côte Bleue Marine Park, 4) Isola di Bergeggi MPA, 5) Isola di 
4131 Ustica MPA, 6) Isole Tremiti MPA, 7) Porto Cesareo MPA, 8) Portofino MPA, 9) Tavolara-Punta Coda Cavallo

132 MPA, 10) Torre Guaceto MPA, 11) Zakynthos National Marine Park.

9134 Table 1. Description of the 11 MPAs investigated

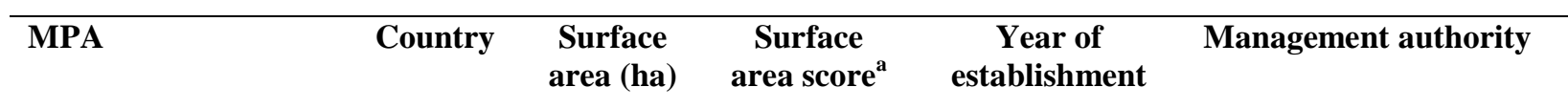

\begin{tabular}{lccccc}
\hline $\begin{array}{l}\text { Bouches de Bonifacio } \\
\text { Natural Reserve }\end{array}$ & France & 79,640 & 5 & 1999 & \\
\hline $\begin{array}{l}\text { Cala Ratjada- } \\
\text { Penara }\end{array}$ & Spain & 11,286 & 4 & 2007 & Spa
\end{tabular}

Peninsula de Llevante

Marine Reserve

\begin{tabular}{lllll}
\hline $\begin{array}{l}\text { Côte Bleue Marine } \\
\text { Park }\end{array}$ & France & 9,873 & 4 & 1983 \\
& & &
\end{tabular}

\begin{tabular}{lcccc}
\hline $\begin{array}{l}\text { Isola di Bergeggi } \\
\text { MPA }\end{array}$ & Italy & 215 & 1 & 2007 \\
\hline Isola di Ustica MPA & Italy & 15,951 & 4 & 1986 \\
\hline Isole Tremiti MPA & Italy & 1,466 & 2 & 1989 \\
\hline Porto Cesareo MPA & Italy & 16,654 & 4 & 1997 \\
& & & & \\
\hline Portofino MPA & Italy & 346 & 1 & 1999
\end{tabular}

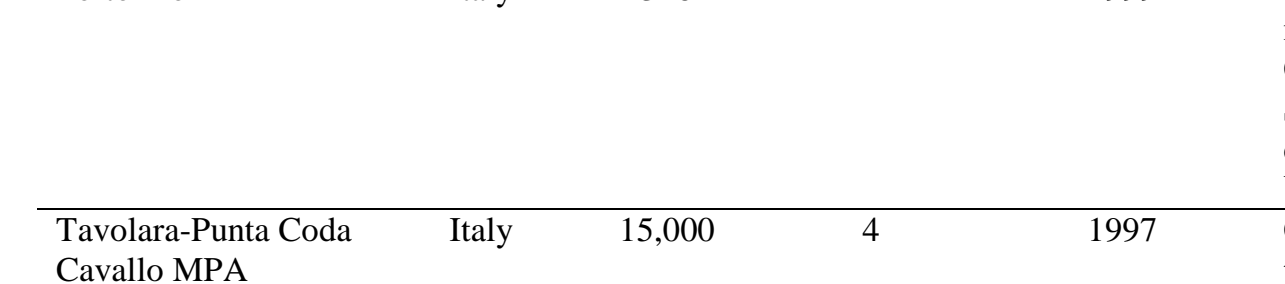

\begin{tabular}{llllll} 
& & & & \\
\hline Torre Guaceto MPA & Italy & 2,200 & 2 & 1991 & Con
\end{tabular}




\subsection{Data collection}

Questionnaires (Appendix A, Text A.1) were drawn up, tested and then always administrated by the same person to MPA managers and staff members via structured face-toface interviews ( $n=9$ MPAs) or Skype calls ( $n=2$ MPAs). The amount and the quality of the data we gathered were not biased by the method employed (Sturges \& Hanrahan, 2004), especially considering that questions referred to factual data and not to opinions - a procedure that eliminated the possibility of bias and misleading answers. In addition to the interviews, we completed the collection of data for each MPA by consulting management plans and internal reports. A total of 104 variables (e.g., see subsections 2.3.1-2.3.4) have been taken into account. We investigated every MPA conceiving it as an organization and mainly focusing on internal organizational variables. Due to the intrinsic complexity of the proposed framework, we decided to set aside some variables, e.g. those related to the MPA relationships between managers and employees. Due to the complexity of their monitoring process, we also decided to set aside other external relevant variables, such as the relationships between the MPA and its partners or stakeholders, except for the core activity of surveillance.

\subsection{Data treatment}

Several organizational dimensions have been characterized through the analysis of single variables. A hierarchy of indices has been developed to summarize the management performance assessment (Fig. 3). To build the indices, the relevant information has been collected through different components (items and targets), each evaluated with specific metrics depending on its specific nature (e.g., categories or numerical variables). Each component has also been ranked and scored in order to obtain five isometric 1st order indices. The 1st order indices were further combined into two aggregated indices (Fig. 3). The indices taken into account are presented in the following paragraphs. 


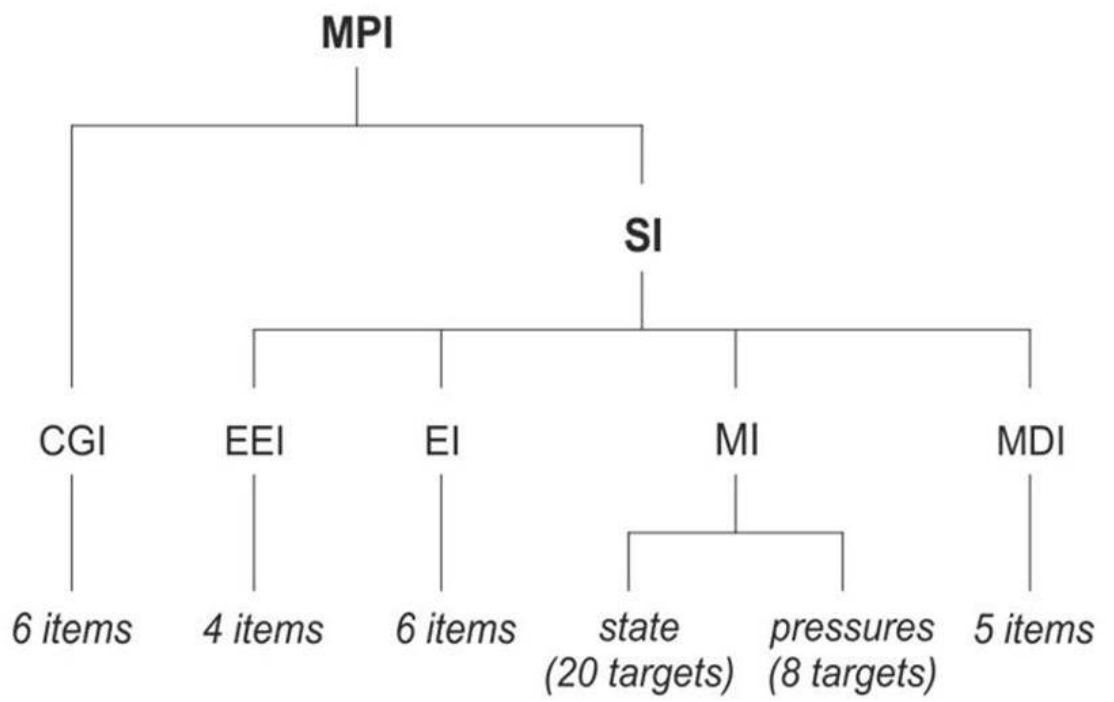

Fig. 3. The hierarchy of the indices implemented in this study. Components are in italics, $1^{\text {st }}$ order indices in roman, aggregated indices in bold. Top to bottom: MPI = management performance index; $\mathrm{SI}=$ strategy index; CGI = culture and goal index; $\mathrm{EEI}=$ environmental education index; $\mathrm{EI}=$ enforcement index; $\mathrm{MI}=$ monitoring index; $\mathrm{MDI}$ $=$ management data index.

\subsubsection{Legal status and authority characterization}

We investigated the legal status of the management body of the 11 MPAs by considering six variables:

i) pre-existence of the management body before creation of the MPA (yes/no);

ii) nature of the management body (public/private/mixed);

iii) management body constituted by institution/s having the legal power to issue penalties to offenders (yes/no);

iv) management body with the legal authority to directly employ the manager and the staff (only the manager/both the manager and the staff/neither of the two);

v) management body directly allocating its own police officers for surveillance (when it is the case) (yes/no);

vi) MPA staff members with the legal power to issue penalties to offenders (yes/no).

\subsubsection{Characterization of the organizational structure and size}

The organizational structure has been assessed on the basis of eight variables:

i) centralization, i.e. where the decisional power is held (national level/regional level/local level);

ii) hierarchy, defined as the number of different levels of authority within the management body; 
iii) organizational size: the workforce on which the MPA can rely, expressed here as the ratio between the number of full-time equivalents (FTE, the equivalent number of employees working full-time in an organization) and the total surface area of the MPA in $\mathrm{km}^{2}\left(\mathrm{FTE} / \mathrm{km}^{2}\right)$. It is important to underline again that herein MPA size does not refer to the surface area of the MPA, but to the workforce in an MPA;

iv) operative personnel ratio, defined as the ratio between the number of full-time operative (Op) workers (e.g. doing surveillance in the field) and the total number of FTE (Op/FTE);

v) personnel stability, i.e. the ratio between the number of full-time permanent employees (PE) and the total number of FTE (PE/FTE);

vi) manager stability, in terms of:

a) manager position (non-permanent position/permanent position);

b) ratio between the age (A, in years) of the MPA since its implementation and the number of managers appointed (M) (M/A);

vii) manager professionalism, defined as the manager's educational level, training and work experience, assessed on the basis of seven features:

a) educational level (Bachelor/Master degree/PhD);

b) degree consistent with natural resource management issues (yes/no);

c) specific training in marine topics after graduation (yes/no);

d) previous employment in an environmental or marine sector (yes/no);

e) previous employment in MPAs (yes/no);

f) specific training in management (yes/no);

g) previous management experience, e.g. in companies (yes/no).

\subsubsection{Characterization of networking for surveillance}

We also focused on the effort made by the management body to collaborate with the 211 police body (if present) legally responsible for enforcing the MPA (e.g. the coastguard). 212 'Network' in OS is defined as the number and kind of collaborative relationships that the 213 organizations may activate with their 'environment', i.e. everything outside the organization's 214 boundaries (Powell, 1990; Uzzi, 1996). We considered three variables:

215 i) presence of a police body responsible for enforcing the MPA (yes/no/the 'police' function is 216 provided by MPA staff); 
ii) active collaboration (e.g. working together in the field, sharing funds) between the MPA management body and the police body (yes/no);

iii) surveillance data available, in terms of 'hours' carried out by the police body (yes/no).

\subsubsection{Management performance assessment}

MPA management performance was assessed by combining two indices, the Culture \& Goal Index (CGI) and the Strategy Index (SI), into a final aggregated index.

The Culture \& Goals Index (CGI) assesses the effort deployed in planning the long term future, through the formalization of the mission and vision, and the short term future, through setting the goals. We characterized the "type of mission" that each MPA formalized, i.e. the main purpose the MPA was created for, considering 5 categories: conservation, education, monitoring and research, recreation, resources management (Bianchi et al., 2012). Mission and vision are part of the culture (a body of shared values and governing ideas), which is crucial for planning the future of any organization (Etzioni, 1964; Nanus, 1992). It also measures the effort deployed by each MPA management body in formalizing, periodically updating and quantifying its goals. The goals are necessary tools to assess the progress of MPA effectiveness (Ervin, 2003; Kay \& Alder, 1999), but progress is measureable only if the goals are themselves measureable (Grafton \& Kompas, 2005). The CGI is a 1st order index constituted by 6 items, and ranges from 0 to 8 (Appendix A, Table A.1).

The Strategy Index (SI) is an aggregated index. It is constituted by four 1st order indices, each evaluating the planning and the realization of the four main activities implemented within a MPA: Environmental Education Index (EEI), Enforcement Index (EI), Monitoring Index (MI), and Management Data Index (MDI) (see Appendix A, Table A.2 to A5 for more details). The scores of each of the 4 activity indices have been ranked to range between 0 and 8 . Averaging the ranks for each activity gives the score of the SI, according to the formula: SI= (EEI+EI+MI+MDI)/4. The maximum score for the SI is therefore 8 .

The Management Performance Index (MPI) was devised to integrate the Culture \& Goals Index (CGI), seen as a measure of what should be done, and the Strategy Index (SI), seen a synoptic expression of what is actually done to achieve MPA goals. The basic concept beyond the MPI is that neither good ideas and targets (GI) nor impressive activities (SI) alone are 
enough: a satisfactory management system requires both. The MPI is computed through the formula: $\mathrm{MPI}=\sqrt{ }\left(\left(\mathrm{CGI}^{2}+\mathrm{SI}^{2}\right) / 2\right)$, so that its maximum score is again 8 .

\section{Results}

Below, we report the results obtained for each of the categories of variables and/or indices identified in the previous section.

\subsection{Characterization of legal status and authority}

Four MPAs out of eleven are managed by a pre-existing body. The remaining MPAs are managed by bodies specifically and exclusively created to manage the MPA (along with a terrestrial National Park in the case of Tremiti MPA). Nine management bodies are public organizations or consortia of public bodies. Torre Guaceto and Zakynthos are managed by hybrid public and non-profit organization.

Staff members of the management body have the legal power to inflict penalties in the Bonifacio MPA only. All the other MPAs here considered have a management body that includes at least one institution having the power to inflict penalties (e.g. fines, confiscations) on offenders. Public institutions that are part of the management bodies at Bergeggi and Portofino MPAs (municipality and district, respectively) allocate police officers to help the management body to enforce the MPA.

All the eleven MPAs have the legal power to directly employ the managers. The management bodies of Bonifacio, Cala Ratjada, Côte Bleue and Zakynthos also have the legal power to employ staff members. The seven Italian MPA management bodies do not have any legal power to hire any staff.

\subsection{Characterization of the organizational structure and size}

Nine MPAs are managed at local level, Bonifacio is managed at regional level, and Cala Ratjada is managed simultaneously at national and regional level (via the collaboration between the National Ministry of Environment and Rural and Marine Affairs, and the Regional government of the Balearic Islands). Ten MPAs have four hierarchical levels (president, one or 
4277 two management boards, manager, and staff). Cala Ratjada has 6 hierarchical levels (minister, 6278 general secretariat, general director, subdirector, two managers, and staff).

279

The MPA organizational size is measured as the ratio between Full Time Equivalent positions and surface area $\left(\mathrm{FTE} / \mathrm{km}^{2}\right.$ ). It varies from 0.01 (Ustica) to 2.31 (Portofino) (mean = $0.52 \pm 0.79 \mathrm{SD}$ ), meaning that there is one FTE per $2 \mathrm{~km}^{2}$ of surface area on average (Table 2). The operative personnel ratio (Op/FTE) ranges from 0.11 (Tremiti) to 0.89 (Bonifacio) (mean=0.56 $\pm 0.23 \mathrm{SD}$ ) (Table 2). The personnel stability ratio (PE/FTE) varies from 0 (Porto Cesareo) to 0.89 (Tremiti) (mean=0.34 $\pm 0.27 \mathrm{SD}$ ), meaning that one third of the staff members are permanent employees on average (Table 2). Thus, these three organizational dimensions show high variability in the sample of MPAs considered (Fig. 4a and $4 b$ ).

Table 2. Scores of the organizational dimensions and of the indices of management performance for each MPA studied here.

\begin{tabular}{|c|c|c|c|c|c|c|c|c|c|c|c|}
\hline $\begin{array}{c}\text { Organizational } \\
\text { dimensions }\end{array}$ & Bergeggi & Bonifacio & $\begin{array}{c}\text { Cala } \\
\text { Ratjada }\end{array}$ & $\begin{array}{l}\text { Côte } \\
\text { Bleue }\end{array}$ & Portofino & $\begin{array}{c}\text { Porto } \\
\text { Cesareo } \\
\end{array}$ & Tavolara & $\begin{array}{c}\text { Torre } \\
\text { Guaceto } \\
\end{array}$ & Tremiti & Ustica & Zakynthos \\
\hline Size & 1.76 & 0.04 & 0.07 & 0.08 & 2.31 & 0.03 & 0.05 & 0.77 & 0.12 & 0.01 & 0.47 \\
\hline $\begin{array}{l}\text { Operative personnel } \\
\text { ratio }\end{array}$ & 0.34 & 0.89 & 0.65 & 0.71 & 0.5 & 0.47 & 0.5 & 0.79 & 0.11 & 0.36 & 0.81 \\
\hline Personnel stability & 0.37 & 0.71 & 0.49 & 0.41 & 0.25 & 0 & 0.13 & 0.06 & 0.89 & 0.29 & 0.1 \\
\hline Manager stability & 3.5 & 7.5 & 7 & 32 & 4.33 & 9 & 11 & 14 & 6.33 & 3.83 & 7 \\
\hline $\begin{array}{l}\text { Culture and goals } \\
\text { index }\end{array}$ & 4 & 3 & 2 & 4.5 & 6.5 & 5.5 & 4.5 & 6.5 & 4 & 4 & 2 \\
\hline $\begin{array}{c}\text { Environmental } \\
\text { education index }\end{array}$ & 4 & 6 & 2 & 6 & 2 & 3 & 4 & 6 & 3 & 4 & 6 \\
\hline Enforcement index & 5 & 5 & 4 & 4 & 4 & 3 & 3 & 5 & 2 & 2 & 7 \\
\hline Monitoring index & 2 & 3 & 1 & 5 & 2 & 2 & 3 & 4 & 1 & 2 & 3 \\
\hline $\begin{array}{l}\text { Management data } \\
\text { index }\end{array}$ & 4 & 6 & 6 & 6 & 0 & 1 & 5 & 6 & 5 & 2 & 6 \\
\hline Strategy index & 3.75 & 5 & 3.25 & 5.25 & 2 & 2.25 & 3.75 & 5.25 & 2.75 & 2.50 & 5.50 \\
\hline $\begin{array}{c}\text { Management } \\
\text { performance index }\end{array}$ & 3.88 & 4.12 & 2.70 & 4.89 & 4.81 & 4.20 & 4.14 & 5.91 & 3.43 & 3.34 & 4.14 \\
\hline
\end{tabular}



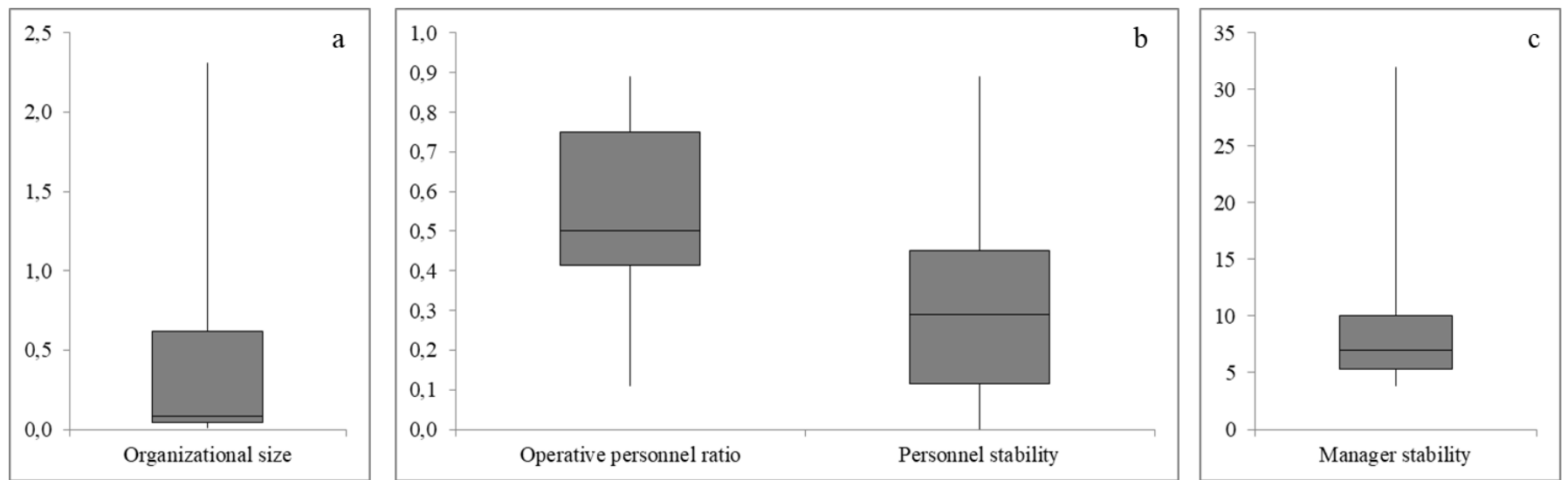

Fig. 4. Box plots showing the median (horizontal line), first and third quartiles (limits of the box), and minimum and maximum values (whiskers) of the organizational size (panel a), the operative personnel ratio and personnel stability (panel b) and the manager stability (panel c) for the 11 MPAs investigated.

The managers of Bergeggi, Portofino, Porto Cesareo, Tavolara and Ustica hold nonpermanent positions, while the managers of the other MPAs have permanent positions. The ratio between the age of the MPAs and the number of managers appointed (M/A, manager stability) varies from 3.5 (Bergeggi) to 32 (Côte Bleue) (mean=9.59ะ 8.06 SD). Côte Bleue had just one manager since its implementation, while Bergeggi had two managers but, as it is a young MPA (7 years old), the value of this ratio is inevitably low. Ustica is the MPA that had the highest number of managers (6 successive managers in 23 years). Also this feature shows a high variability among the MPAs considered (Fig. 4c).

Concerning the professionalism of the MPA managers, the picture is again extremely variable among the eleven MPAs considered. Three MPA managers out of eleven have a PhD, while the others have a Bachelor or Master degree. Nine out of eleven managers received an academic education in environmental and resource management. Nine and seven out of eleven managers attended training courses on marine/environmental issues or management issues, respectively, after their degree. Apart from the academic background, ten out of eleven managers had previous employment in the marine/environmental sector, four out of eleven in the business management sector, and four out of eleven were already employed previously in the MPA sector. In some MPAs (e.g. Cala Ratjada and Tavolara), the education of the manager was diversified, varying from a $\mathrm{PhD}$ or Bachelor/Master degree in environmental (often marine) subjects to training and previous employment in the business management sector or local public 
administration (e.g. Municipality). In the case of other MPAs, the educational background and work-political experience of the managers was more limited.

\subsection{Characterization of networking for surveillance}

The inter-organization cooperation developed in order to carry out surveillance is very heterogeneous. As previously evidenced, in all the MPAs considered, there are one or more police bodies responsible for enforcement. Only at Bonifacio do some staff members have the same legal power as the police officers, so there is no strict need in this case for the MPA to formalize collaboration with the police authorities, this core function being incorporated within the MPA management body itself.

At Zakynthos, many hours of surveillance in the MPA are performed by the staff jointly with police officers. The police body also makes available the data on the hours of surveillance carried out independently. At Côte Bleue too, the staff carry out surveillance jointly with police officers, even if only for a few hours per year. At Bergeggi, Porto Cesareo and Tremiti, MPA management bodies share funds with the police bodies to finance surveillance activities. Bergeggi, Porto Cesareo, Portofino, Tavolara, Torre Guaceto, Tremiti and Zakynthos share the surveillance data with the police body.

\subsection{Management performance assessment}

Portofino and Torre Guaceto achieved the highest values for the Culture \& Goals Index (CGI, Table 2). These MPAs made an attempt to formalize their vision, even though their vision statements are rather inaccurate/imprecise. These two MPAs adopted a high percentage of measurable goals (69\%, and 55\%, respectively). All the eleven MPAs have formalized their mission: "conservation" is the stated mission for ten MPAs; at Cala Ratjada, the declared mission is "resources management". Cala Ratjada and Zakynthos do not have formal goals, so their CGI obtained the lowest scores among the MPAs considered (Table 2). As for the Strategy Index (SI), Zakynthos, Côte Bleue, Torre Guaceto and Bonifacio MPAs achieved the highest values, followed by Bergeggi and Tavolara, and then the remaining MPAs (Table 2).

Looking in greater depth into the specific 1st order indices of the SI for each MPA, the highest score for EEI (Environmental Education Index) is achieved by Zakynthos (Fig. 5), which gets the highest value for three out of the four items composing the EEI (see Appendix A, Table 
A.2 for more details). None of the MPAs considered assessed the efficacy of environmental education projects. The lowest EEI scores are obtained by Portofino and Cala Ratjada, where the environmental education projects were only carried out occasionally. Zakynthos again gets the highest score for the EI (Enforcement Index) (Fig. 5), because of the significant number of hours of surveillance that the MPA staff performs both independently and jointly with the police body. The lowest score is recorded by Ustica, due to the low number of hours of surveillance performed by the MPA staff and the police body. The only MPA where the staff members carry out the legal enforcement is Bonifacio, but its EI is lower than that of Zakynthos due to the very extensive surface area of Bonifacio. The MI (Monitoring Index) displays in general fairly low values (Fig. 5), due to the low number of targets (e.g. species) that are usually monitored (mean number of targets $=12 \pm 4.8$ ) or the short-term nature of monitoring activities. With regard to the MDI (Management Data Index), Bonifacio, Cala Ratjada, Côte Bleue, Torre Guaceto and Zakynthos record quite high scores (Fig. 5), achieving the maximum value for 3 out of the 5 items of the index (see Appendix A, Table A.5 for more details). At Portofino, the MDI equals 0 because the staff does not perform any surveillance, and education projects are not monitored for their effects. MDI scores obtained by many MPAs are generally low, mainly because the MPAs do not assess the environmental education effectiveness (Fig. 5). 


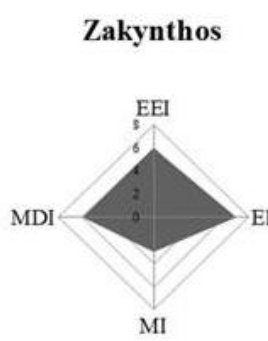

Bergeggi

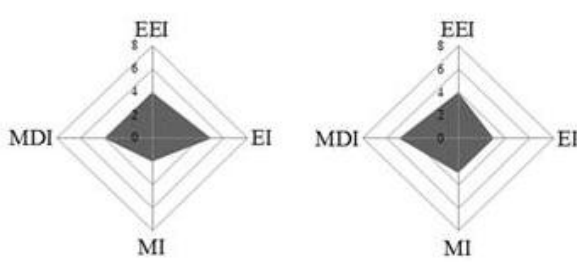

Ustica
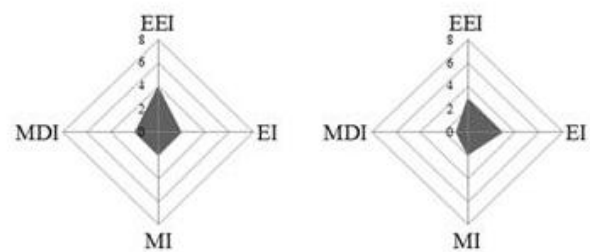

Cala Ratjada

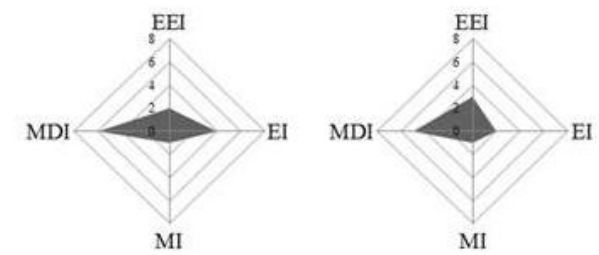

Porto Cesareo

MI
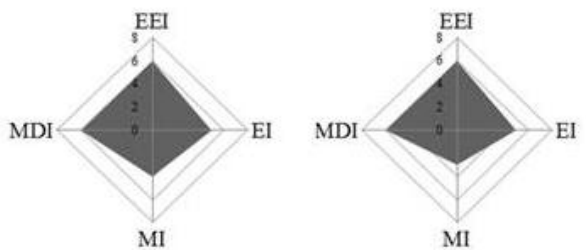

Tremiti

Fig. 5. Scores of the Environmental Education Index (EEI), the Enforcement Index (EI), the Monitoring Index (MI) and the Management Data Index (MDI) for the 11 MPAs considered. Note that no MPA achieves the theoretical maximum for all indices.

So although the EEI, EI, MI and MDI provided fairly different contributions to the overall Strategy Index (SI), which results from their average, SI represents a synoptic assessment of the activities performed at the MPAs studied here. Zakynthos is the most active (Table 2), but the low value for MI (Fig. 5) suggests that there is still room for improvement. In addition, Bonifacio, Côte Bleue and Torre Guaceto exhibit high scores for the SI (Table 2), but monitoring and enforcement (measured by MI and EI) are not optimal yet (Fig. 5). Ustica, Porto Cesareo and Portofino are the MPAs with the lowest SI scores (Table 2), which suggests the need for improvement in three or four management components.

Both CGI and SI show a high variability, with a wide range of scores, in the MPAs considered. None of the MPAs reaches the maximum score for either index (Fig. 6). Coupling CGI and SI into the Management Performance Index (MPI; Table 2) highlights that Torre Guaceto is distinctly the top-performer, followed by Côte Bleue and Portofino, whereas Tremiti, Ustica and Cala Ratjada come last. In addition, for this index a high variability is evident (Fig. 
4382 6). However, four different situations can be distinguished (Fig. 7): i) Torre Guaceto and Côte 6383 Bleue obtain a high MPI because of their significant effort in carrying out fundamental activities

Fig. 6. Box plots showing the median (horizontal line), first and third quartiles (limits of the box), and minimum and maximum values (whiskers), of the Culture \& Goals (CGI), Strategy (SI) and Management Performance (MPI) Indexes for the 11 MPAs investigated.

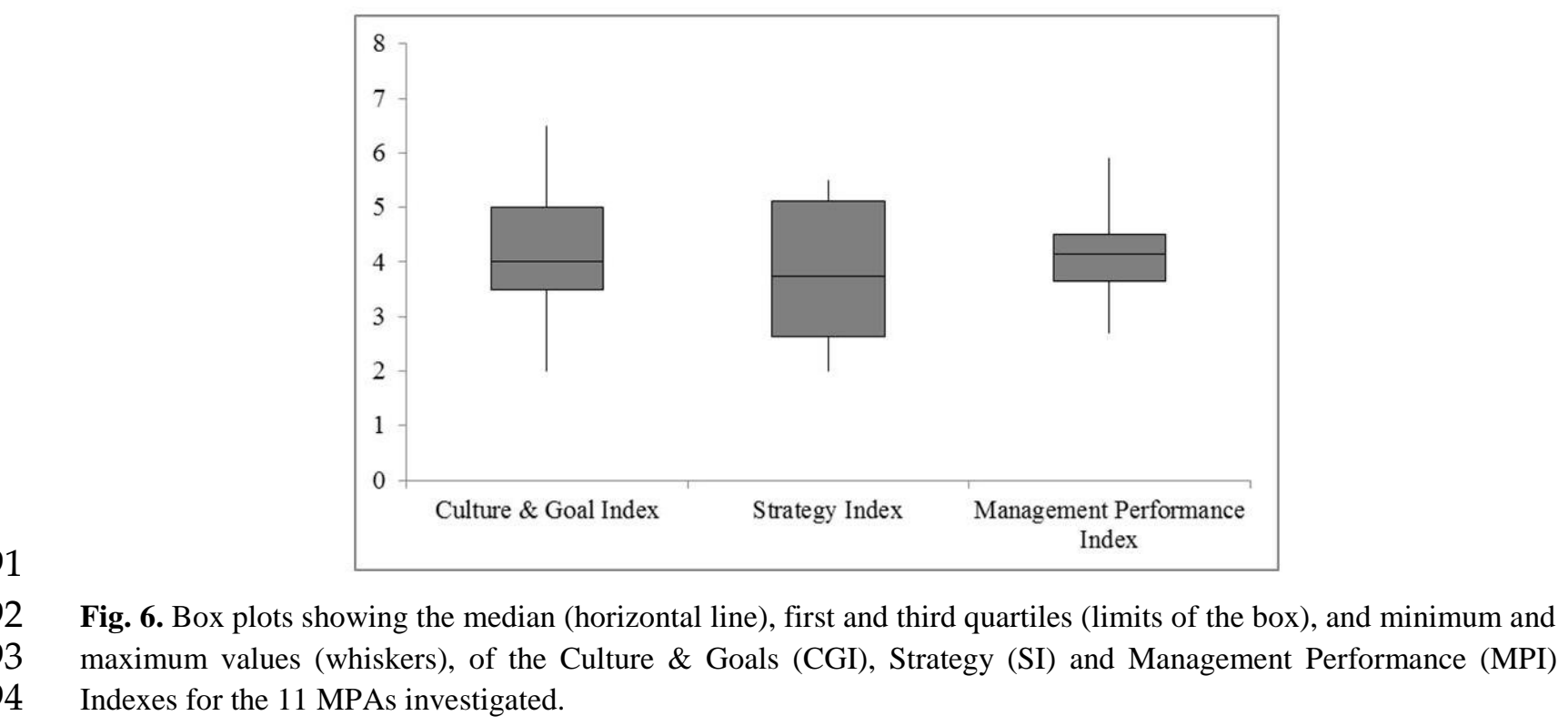
educational activities); iv) the remaining MPAs are insufficient and/or incomplete in both their planning and implementation of activities.

90
linked to well-defined projects (both CGI and SI are high); ii) Zakynthos and Bonifacio are quite active but pay little attention to the formalization of vision, mission and goals (SI is high but CGI is low); iii) Tavolara, Porto Cesareo and Portofino conducted appropriate projects but invested less in assessing, planning and accomplishing their activities (e.g. monitoring the effect of

(1)




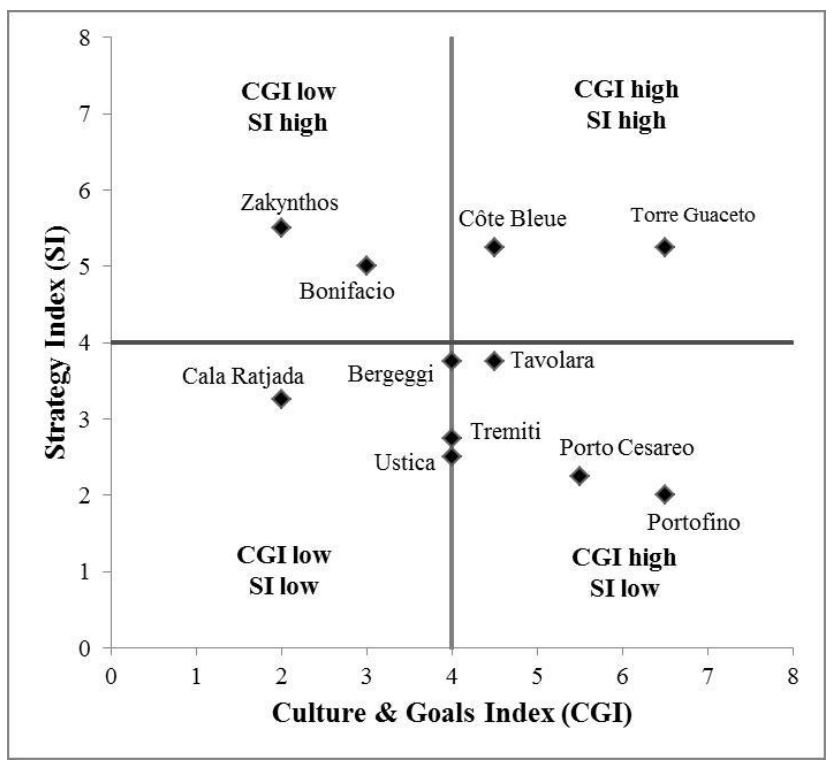

Fig. 75. Scores of the Strategy Index (SI) and the Culture and Goals index (CGI) for the 11 MPAs studied. Crossing the two indices, four different scenarios emerge (see subsections 3.4).

\section{Discussion}

The present study underlines the importance of management features in MPA science (Gill et al., 2017; Hargreaves-Allen et al., 2017; Worm, 2017) and offers a novel perspective and framework to evaluate and interpret MPA performance. It supplies new tools, such as a standardized questionnaire, created to collect factual data (and not opinions of the interviewees), and simple indices. The collection of factual data through an objective approach is the most important characteristic of our methodology, allowing applicability to different geographical contexts and scales, and making it different from the other tools so far employed (e.g., METT, World Bank MPA Score Card and RAPPAM) (Ervin, 2003; Stolton et al., 2007; Staub \& Hatziolos, 2004). The framework provided also differs from the tools previously employed because it takes advantage of the experience gathered through research in another science (OS). This can be useful in helping MPA managers and policy makers to solve problems and assess several crucial management aspects (e.g. centralization, professionalism, enforcement) (Claudet et al., 2008; Guidetti et al., 2008; Montefalcone et al., 2009), which are often neglected in conservation science. We tried to make our assessment objective as far as possible and to avoid social biases. For example, in the assessment of the enforcement, we did not consider the number of penalties inflicted on the offenders because punitive actions are not always the best deterrent, 
and other strategies or investments can be more effective to enforce an MPA (e.g. cooperation, trust, leadership) (Micheli \& Niccolini, 2013; Pieraccini et al., 2016).

The present study provides a tool for the assessment of MPA management performance that allows comparison between the MPAs. In particular, policy makers responsible for the management of national MPAs (and the systems they form) can use it to integrate and assess organizational factors to compare management performance among MPAs. It was not our purpose to create a completely new Management Performance System, and furthermore we did not focus on the entire process within an organization that may influence employees' behaviour and implement specific strategies (Anthony \& Govindarajan, 1998). However, such an approach could be taken into account in further studies.

One of the most significant difficulties we faced in this study was the limited availability of data (Fox et al., 2014; Worm, 2017). MPAs are often small and sometimes young organizations that normally do not have enough resources for exhaustive monitoring. Ecological and management data, when they are collected, are often not collected within the same time frame, and not stocked or reported in a standardized way (Claudet \& Guidetti, 2010; Gill et al., 2017). Such shortcomings make it difficult to couple ecological and management data and extract generalizations, something which needs an appropriate sample size. This is the case also for Gill et al. (2017), who assessed MPA management effectiveness at global scale, finally taking into account 64 MPAs due to the limited data availability. So our sample size (11 MPAs at Mediterranean scale) should be considered in the light of the limited availability of management and bio-ecological data from MPAs (Gill et al., 2017).

The first clear evidence emerging from this study is the heterogeneity displayed by the eleven MPAs investigated. The heterogeneity concerns the legal status, the pre-existence and the authority to inflict penalties and employ managers and staff of the management body. This suggests that the process of creation and subsequent management of a MPA is extremely variable, with possible repercussions on the MPA performance and effectiveness (Francour et al., 2001). Further studies should be done to urgently investigate the effects of these features on MPA management effectiveness.

The MPAs taken into account are more homogeneous when the centralization is taken into account. However, the existence of MPAs managed at different levels of centralization (local, regional and national) suggests the need to carry out studies to investigate how 
centralization could affect MPAs' management effectiveness. We can observe that the management at national level may help in developing a unitary organizational system of guidance, service and support for the individual MPAs (such as systematic training opportunities for managers or employees, volunteer programs). This is the case, for instance, for the National Marine Sanctuaries Office of the National Oceanic Atmospheric Administration (NOAA) in the USA (Morandi et al., 2012). On the other hand, decentralized management levels can enhance the customer orientation in public organizations (Andrews et al., 2006; Osborne \& Gaebler, 1992), which, in the MPA context, could imply a closer connection with the local communities. An interesting option could be a mixed system: i) the national (or supranational, such as the EU) management level (e.g., through an inter- or governmental agency) harmonizes and standardizes some aspects of the MPAs' functioning, structure and management, such as legal status, authority, internal hierarchy, stability and functions of the staff and support services (e.g. a national MPAs website or a national volunteer program); ii) the local level helps in adapting the MPA management to the local context (e.g. adopting the right contingent solutions for specific threats or pressures, integrating within the co-management specific categories of stakeholders, adapting management measures to local cultures) (White et al., 2002). However, when several bodies are involved in making decisions at different levels regarding the management of a single MPA, it requires a major effort to coordinate decisions and activities in order to be effective (Rife et al., 2013).

Furthermore, the hierarchy of the eleven MPAs considered gives quite homogeneous results. A proper number of hierarchical levels to increment MPA management effectiveness is probably not the same in each MPA context, but it is known that an excessive number of hierarchical levels may interfere with effective communication up and down the organization structure (Pugh, 1973). Further studies should focus on possible alternatives to hierarchical structures for the MPAs that lead to the enhancement of the management effectiveness.

The eleven MPAs considered were extremely variable also in terms of organizational size and structure (operative personnel ratio, personnel and manager stability, manager professionalism). So far, no studies have investigated the effects of such features on MPAs management effectiveness. However, studies focusing on organizations other than MPAs have shown that a small organizational size could negatively affect the productivity and services provided by public and private organizations (Gooding \& Wagner, 1985). A poorly balanced 
staff structure, specifically the presence of too many administrative workers (which sometimes it is needed to deal with an excessive and complex bureaucracy of the system), could significantly decrease the effectiveness of the organization (Bidwell \& Kasarda, 1975). High personnel stability reduces the costs of employment transactions, promotes the creation of effective working relationships, improves motivation and enables management continuity (Coase, 1937; Leana \& Van Buren, 1999; Pfeffer, 1998). In the MPA context, the relative stability of managers and employees is particularly important, as the most significant strategic MPA targets, particularly ecological and socio-economic responses (e.g. increase of fish biomass and size, and related enhanced fishing catches), require long periods of time (decades) to be achieved (GarcíaRubies et al., 2013). A high degree of professionalism could positively affect the effectiveness of the manager, and probably of the employees in general, which may impact in turn the organizational effectiveness and the achievement of the goals (Daft, 1978; Damanpour et al., 1989; Vigoda-Gadot, 2007).

The characterization of the networking related to the surveillance of the MPAs showed that the collaboration among MPA management bodies and police bodies is often limited. The joint activity of MPA staff and police officers could enable the pooling of competences (e.g. knowledge of the legal framework, knowledge of the territory, correct classification of protected species included in international protocols such as the Habitat Directive of the EU) so as to improve the effectiveness of surveillance activities. This is consistent with the generally accepted principle that cooperative attitudes can favour the sharing of different skills and consequently improve the effectiveness of organizations' strategies (Alter \& Hage, 1993; Greenhalgh, 2001; Hamel, 1991). Even though it may appear surprising for organizations such as Marine Protected Areas, the availability of data regarding the surveillance activities carried out by MPA staff and/or police bodies is very limited, and often the available data are raw, inaccurate and sometimes entirely unreliable. The absence of accurate and reliable data on MPA surveillance makes it difficult to set up a proper adaptive management system to optimize costs and make MPAs increasingly effective (Holling, 1978; Parma AM \& NCEAS Working Group on Population Management, 1998; Walters \& Hilborn, 1978). In the Mediterranean MPA context, the existing cooperation is more the result of personal initiatives of managers who have decided to invest in networking, than the outcome of structural measures aimed at making MPAs effective. 
The eleven MPAs are highly variable also in terms of the indices considered. The scores

for Culture and Goals Index (CGI) revealed that, unexpectedly, the importance of formalizing the vision, mission and measurable goals is not generally understood yet in the context of Mediterranean MPAs. In OS, it has been demonstrated that the formalization of the vision, mission and measurable goals enables organizations to achieve higher effectiveness (Baetz \& Bart, 1996; Lipton, 1996; Kantabutra, 2008; O'Brien \& Meadows, 2000). In addition, a clearer perspective on the future, in both the long term (vision) and the short term (goals), and similarly a clear mission statement, might improve the consistency and effectiveness of the strategy of any organization, and provide a basis for developing coherent effectiveness assessment systems (Sawhill \& Williamson, 2001). The heterogeneity in the results of the Strategy Index (SI) is due to the investment in one or more activities (e.g., enforcement, education, monitoring, data collection), which is the result of the personal initiative or choice of each single MPA manager. This is also surprisingly true for the monitoring, the activity that provides the information on the effectiveness of the management process and enables decisions to be made concerning what the management body needs to change in the management strategy, or where and when additional effort is needed. Such heterogeneity in the strategy and the related activities is also determined by the difficulties faced during the management process: paucity of staff and funding (e.g. for enforcement, monitoring, education), lack of political will (especially for the enforcement), underestimation of the importance of the availability of crucial data (e.g. monitoring and management data) for the setting up of the adaptive management of MPAs and the assessment of the effectiveness of management actions (Balmford \& Whitten, 2003; Day et al., 2012; Thur, 2010; Walters \& Hilborn, 1978). Accounting for the effort devoted to the monitoring enables evaluation of the ability/possibility of the organizations to assess the achievement of their goals. The Management Performance Index (integrating the effort made to plan the future and accomplish the related activities in the MPAs) underlined a surprising overall heterogeneity in terms of the attention and importance paid to the different aspects of the management process by the MPAs. 


\section{Conclusions}

This exploratory study applied OS principles and framework to develop a novel method to characterize crucial MPA features, such as authority, structure, organizational size and networking, and to assess and explain MPA performance (Horigue et al., 2014). A number of indices were also developed that offer a basis for summarizing and better understanding the weaknesses of each MPA. Such indices clearly indicate the management aspects that need to be improved to enhance MPA performance, which in turn can improve MPA effectiveness.

Our exploratory research, although focused on a limited number of case studies, provides a partial picture of the reality investigated. The confirmation of the the validity of the specific results produced by this exploratory study can be obtained only by broadening the sample of the MPAs investigated, and repeating the the survey in other ecoregions.

Being conscious of those intrinsic limitations, we can say that our exploratory research showed that some answers to MPA performance issues could be found by looking more in depth into their organizational setting. Without any pretension of creating a complete and new Management Performance System (MPS) (Anthony and Dearden, 1980), the framework proposed here can offer useful information and indications in particular to MPA policy makers (at regional and national level) as a basis for interpreting the organizational reasons why MPAs achieve different level of performance, and consequently improving the implementation of strategy for an entire MPA system. At the same time, some of the organizational dimensions assessed here can be useful sources of information for single MPA managers for "improving the likelihood of their organization to implement their [MPA] strategy" (Anthony \& Govindarajan, 1998). In this perspective, our exploratory study can provide useful indications, tools and methodological clues, especially for policy makers responsible for the management of national MPA systems to include organizational factors within their national Management Control System (MCS) and also for single MPA managers to include some organizational factors within their single MPA's MCS.

Should our results be confirmed by more exhaustive sampling, we can imagine that a more standardized framework related to MPA management at EU and Mediterranean scales (e.g. planning and performing strategic activities, prioritizing monitoring targets, standardizing enforcement methods, collecting data on management and education programs) could increase the success of the existing MPAs and produce a catalyzing effect for future developments. An 
improvement of the legal framework also seems to be needed, particularly in order to implement the enforcement of MPAs and the stability of managers and employees.

We strongly believe that the present exploratory research represents a useful step forward in MPA science, providing a new insight towards the understanding of the features that can affect management effectiveness. Improving and enriching on the basis of the OS perspective the methodological approaches to assess MPAs' performance and effectiveness, finally, is pivotal step towards assessing the achievement of international targets to which countries are officially committed, such as the Aichi target 11 of the CBD (2011) or the SDG target 14 (UNEP, 2015).

\section{Acknowledgements}

We would like to thank, first of all, the MPA managers we have interviewed, who provided us with crucial information (in alphabetic order): Frédéric Bachet, Simone Bava, Maddaleine Cancemi, Alessandro Ciccolella, Paolo D'Ambrosio, Giuseppe Di Carlo, Drosos Koutsoubas, Giorgio Fanciulli, Juan Carlos Jorquera Gámez, Silvia Revenga Martínez de Pazos, Augusto Navone, Pasquale Santoro and Laurent Sourbes. We also wish to thank some staff members who kindly provided supplementary data and explanations: Pasquale Baiata, Valentina Cappanera, Eric Charbonnel, Jean-Michel Culioli, Francesco De Franco, Sergio Fai, Tiziana Ferrando, Javier Llorente Palao, Luciana Muscogiuri, Pier Panzalis and Dimitriadis Xaralambos. We want to thank Michael Paul for his invaluable help in reviewing the earlier version of this manuscript.

\section{Funding}

The present study has been supported by the Prince Albert II of Monaco Foundation (Monaco), the Total Corporate Foundation (France), MedPAN (France), the Agence des Aires Marines Protégées (now the Agence Française pour la Biodiversité) and the WWF-MedPO (Italy).

\section{References}

Alter, K., Hage, J., 1993. Organizations working together. Newbury Park, CA: Sage. 
Andrews, R., George, A.B., Walker, R.M., 2006. Subjective and objective measures of organizational performance: an empirical exploration. In Public service performance: perspectives on measurement and management, ed. George A. Boyne, Kenneth J. Meier, Laurence J. O’Toole, and Richard M. Walker. Cambridge, UK: Cambridge Univ. Press.

Anthony, R. N., \& Dearden, J. 1980. Management control systems. Richard D. Irwin.

Anthony, R.N., Govindarajan, V. 1998. Management Control Systems. Irwin McGraw-Hill.

Baetz, M., Bart, C., 1996. Developing mission statements which work. Long. Range. Plann. 4: 526-33.

Balmford, A., Whitten, T., 2003. Who should pay for tropical conservation, and how could the costs be met? Oryx. 37: 238-250.

Ban, N.C., Davies, T.E., Aguilera, S.E., Brooks, C., Cox, M., Epstein, G., et al., 2017. Social and ecological effectiveness of large marine protected areas. Global Enviro. Chang. 43: 82-91.

Barnard, C., 1938. Functions of the executive. Cambridge, Mass., Harvard University Press.

Bianchi, C.N., Parravicini, V., Montefalcone, M., Rovere, A., Morri, C., 2012. The challenge of managing marine biodiversity: a practical toolkit for a cartographic, territorial approach. Diversity. 4: 419-452.

Bidwell, C.E., Kasarda, J.D., 1975. School district organization and student achievement. Am. Sociol. Rev. 40: 55-70.

Bryson, J.M., 1988. A strategic planning process for public and non-profit organizations. Long Range Plann. 21: 73-81.

Claudet, J., Guidetti, P., 2010. Improving assessments of marine protected areas. Aquat. Conserv. 20: 239-242.

Claudet, J., Osenberg, C.W., Benedetti-Cecchi, L., Domenici, P., García-Charton, J.A., PérezRuzafa, Á., et al., 2008. Marine reserves: size and age do matter. Ecol. Lett. 11: 481-89. 
Coase, R., 1937. The nature of the firm. Economica. 4: 386-405.

Convention on Biological Diversity Aichi Biodiversity Targets, 2011. Available from: http://www.cbd.int/sp/targets/.

Daft, R.L., 1978. A dual-core model of organizational innovation. Acad. Manage. J. 21: 193-210.

Daft, R.L., 2010. Organization theory and design, tenth edition. South-Western, Cengage Learning.

Damanpour, F., Szabat, K.A., Evan, W.M., 1989. The relationship between types of innovation and organizational performance. J. Manage. Stud. 26: 587-602.

Day, J., Dudley, N., Hockings, M., Holmes, G., Laffoley, D., Stolton, S., et al,. 2012. Guidelines for applying the IUCN Protected Area Management Categories to Marine Protected Areas. Gland, Switzerland: IUCN.

Dudley, N., 2008. Guidelines for applying protected area management categories. Gland, Switzerland: IUCN.

Edgar, G.J., Stuart-Smith, R.D., Willis, T.J., Kininmonth, S., Baker, S.C., Banks, S., et al., 2014. Global conservation outcomes depend on marine protected areas with five key features. Nature. 506: 216-220.

Emslie, M.J., Logan, M., Williamson, D.H., Ayling, A.M., MacNeil. M., Ceccarelli, D., et al., 2015. Expectations and outcomes of reserve network performance following re-zoning of the Great Barrier Reef Marine Park. Curr. Biol. 25: 983-992.

Ervin, J., 2003. WWF: rapid assessment and prioritization of protected area management (RAPPAM) methodology. Gland, Switzerland: WWF. 648 Etzioni, A., 1964. Modern Organizations. Englewood Cliffs, N.J.: Prentice-Hall. 
Fox, H.E., Holtzman, J.L., Haisfield, K.M., McNally, C.G., Cid, G.A., Mascia, M.B., et al., 2014. How are our MPAs doing? Challenges in assessing global patterns in marine protected area performance. Coast. Manage. 42: 207-226.

Francour, P., Harmelin, J.G., Pollard, D., Sartoretto, S., 2001. A review of marine protected areas in the northwestern Mediterranean region: siting, usage, zonation and management. Aquat. Conserv. 11: 155-188.

Gabrié, C., Lagabrielle, E., Bissery, C., Crochelet, E., Meola, B., Webster, C., et al., 2012. The status of marine protected areas in the Mediterranean Sea. MedPAN \& RAC/SPA. MedPAN Collection.

Gaines, S.D., Lester, S.E., Grorud-Colvert, K., Costello, C., Pollnac, R., 2010. Evolving science of marine reserves: new developments and emerging research frontiers. PNAS. 107: 1825118255.

García-Rubies, A., Hereu, B., Zabala, M., 2013. Long-term recovery patterns and limited spillover of large predatory fish in a Mediterranean MPA. PloS One. 8: e73922.

Gill, D.A., Mascia, M.B., Ahmadia, G.N., Glew, L., Lester, S.E., Barnes, M., et al., 2017. Capacity shortfalls hinder the performance of marine protected areas globally. Nature. 543: 665-669.

Gooding, R.Z., Wagner III, J.A., 1985. A meta-analytic review of the relationship between size and performance: the productivity and efficiency of organizations and their subunits. Admin. Sci. Quart. 462-481.

Grafton, R.Q., Kompas, T., 2005. Uncertainty and the active adaptive management of marine reserves. Mar. Policy. 29: 471-479. 
Greenhalgh, L., 2001. Managing strategic relationship: the key to business success. The Free Press, New York.

673 Guidetti, P., Baiata, P., Ballesteros, E., Di Franco, A., Hereu, B., Macpherson, E., et al., 2014. 674 Large-scale assessment of Mediterranean marine protected areas effects on fish assemblages. PloS One. 9: e91841.

Guidetti, P., Milazzo, M., Bussotti, S., Molinari, A., Murenu, M., Pais, A., et al., 2008. Italian marine reserve effectiveness: Does enforcement matter? Biol. Conserv. 141: 699-709.

Hamel, G., 1991. Competition for competence and inter partner learning within international strategic alliances. Strategic Manage. J. 12: 83-103.

Hargreaves-Allen, V.A., Mourato, S., Milner-Gulland, E.J., 2017. Drivers of coral reef marine protected area performance. PLoS ONE 12(6): e0179394. https://doi.org/10.1371/journal.pone.0179394

Hockings, M., Stolton, S., Leverington, F., Dudley, N., Courrau, J., 2006. Evaluating effectiveness: a framework for assessing management effectiveness of protected areas. 2nd edition. IUCN, Gland, Switzerland and Cambridge, UK.

Holling, C.S., 1978. Adaptive environmental assessment and management. John Wiley \& Sons.

Horigue, V., Aliño, P.M., Pressey, R.L., 2014. Evaluating management performance of marine protected area networks in the Philippines. Ocean. Coast. Manage. 95: 11-25.

Ingersoll, R.M., 2001. Teacher turnover and teacher shortages: An organizational analysis. Am. Educ. Res. J. 38: 499-534.

Jones, P.J., 2014. Governing marine protected areas: resilience through diversity. Routledge.

Kantabutra, S., 2008. What do we know about vision? JABR. 24: 127-138.

Kay, R., Alder, J., 1999. Coastal management and planning. E \& FN SPON. New York. 
Leana, C., Van Buren, H., 1999. Organizational social capital and employment practices. Acad. Manage. Rev. 24: 538-555.

Lester, S.E., Halpern, B.S., Grorud-Colvert, K., Lubchenco, J., Ruttenberg, B.I., Gaines, S.D., et al., 2009. Biological effects within no-take marine reserves: a global synthesis. Mar. Ecol. Prog. Ser. 384: 33-46.

Leverington, F., Costa, K.L., Courrau, J., Pavese, H., Nolte, C., Marr, M., et al., 2010. Management effectiveness evaluation in protected areas - a global study. Second edition 2010.

Lipton, M., 1996. Demystifying the development of an organizational vision. Sloan Manage. Rev. 37: 83-92.

704 McClanahan, T.R., Marnane, M.J., Cinner, J.E., Kiene, W.E., 2006. A comparison of marine 705 protected areas and alternative approaches to coral-reef management. Curr. Biol. 16: 14087061413.

707 Micheli, F., Niccolini, F., 2013. Achieving success under pressure in the conservation of 708 intensely used coastal areas. Ecol. Soc. 18: 19.

709 Montefalcone, M., Albertelli, G., Morri, C., Parravicini, V., Bianchi, C.N., 2009. Legal

710 protection is not enough: Posidonia oceanica meadows in marine protected areas are not 711 healthier than those in unprotected areas of the northwest Mediterranean Sea. Mar. Pollut. $712 \quad$ Bull. 58: 515-519.

713 Morandi, F., Niccolini, F., Sargolini, M., 2012. Parks and territory. New perspectives and $714 \quad$ strategies. Publisher: List.

715 Nanus, B., 1992. Visionary leadership: creating a compelling sense of direction for your organization. San Francisco, California: Jossey-Bass Inc. 
O'Brien, F., Meadows, M., 2000. Corporate visioning: a survey of UK practice. J. Oper. Res. Soc. 51: 36-44.

Osborne, D. Gaebler, T., 1992. Reinventing government: how the entrepreneurial spirit is transforming the public sector. New York, NY: Plume.

Parma, A.M., NCEAS Working Group on Population Management, 1998. What can adaptive management do for our fish, forests, food and biodiversity? Integrative Biology: Issues, News and Reviews. 1: 16-26.

Parravicini V., Micheli F., Montefalcone M., Morri C., Villa E., Castellano M., Povero P., Bianchi C.N., 2013. Conserving biodiversity in a human-dominated world: degradation of marine sessile communities within a protected area with conflicting human uses. PLoS ONE, 8 (10): e75767.

Pfeffer, J., 1998. The human equation: building profits by putting people first. Cambridge, MA: Harvard University Press.

Pieraccini, M., Coppa, S., De Lucia, G.A., 2016. Beyond marine paper parks? Regulation theory to assess and address environmental non- compliance. Aquat. Conserv. 27: 177-196.

Pomeroy, R.S., Parks, J.E., Watson, L.M., 2004. How is your MPA doing? A guidebook of natural and social indicators for evaluating marine protected area management effectiveness. Gland, Switzerland and Cambridge, UK: IUCN.

Powell, W., 1990. Neither market nor hierarchy: network forms of organization. Res. Organ. Behav. 12: 295-336.

Pugh, D., Hickson, D., Hinings, C., Turner, C., 1968. Dimensions of organization structure. Admin. Sci. Quart. 13: 65-91. 
Pugh, D.S., 1973. The measurement of organization structures: does context determine form?

Organ. Dyn. 1: 19-34.

Rainey, H.G., Steinbauer P., 1999. Galloping elephants: Developing elements of a theory of effective government organizations. J. Publ. Adm. Res. Theor. 9: 1-32.

Rife, A.N., Erisman, B., Sanchez, A., Aburto-Oropeza, O., 2013. When good intentions are not enough...Insights on networks of "paper park" marine protected areas. Conserv. Lett. 6: 200212.

Rodríguez-Rodríguez, D., Rodríguez, J., Malak, D.A., 2016. Development and testing of a new framework for rapidly assessing legal and managerial protection afforded by marine protected areas: Mediterranean Sea case study. J. Environ. Manage. 167: 29-37.

Sala, E., Ballesteros, E., Dendrinos, P., Di Franco, A., Ferretti, F., Foley, D., et al., 2012. The structure of Mediterranean rocky reef ecosystems across environmental and human gradients, and conservation implications. PloS one. 7(2), e32742.

Sawhill, J.C., Williamson, D., 2001. Mission impossible? Measuring success in nonprofit organizations. Nonprofit Manag. Leadersh. 11: 371-386.

Scianna, C., Niccolini, F., Gaines, S.D., Guidetti, P., 2015. 'Organization Science': a new prospective to assess marine protected areas effectiveness. Ocean. Coast. Manage. 116: 443448.

Staub, F., Hatziolos, M.E., 2004. Score card to assess progress in achieving management effectiveness goals for marine protected areas. World Bank, 30.

Stolton, S., Hockings, M., Dudley, N., MacKinnon, K., Whitten, T., Leverington, F., 2007. Management effectiveness tracking tool: reporting progress at protected area sites. World Bank/WWF Alliance by WWF International, Gland. 
462 Sturges, J.E., Hanrahan, K.J., 2004. Comparing telephone and face-to-face qualitative

\section{Tempesta, M., Otero, M., 2013. Guide for quick evaluation of management in Mediterranean} MPAs. WWF Italy, IUCN.

Thur, S.M., 2010. User fees as sustainable financing mechanisms for marine protected areas: an application to the Bonaire National Marine Park. Mar. Policy. 34: 63-69.

UNEP, 2015. Transforming our world: the 2030 Agenda for Sustainable Development.

Uzzi, B., 1996. The sources and consequences of embeddedness for the economic performance of organizations: the network effect. Am. Sociol. Rev. 61: 674-698.

771 Vigoda-Gadot, E., 2007. Leadership style, organizational politics, and employees' performance: 772 an empirical examination of two competing models. Pers. Rev. 36: 661-683.

773 Walters CJ \& Hilborn R. 1978. Ecological optimization and adaptive management. Annu. Rev. $774 \quad$ Ecol. Syst. 9: 157-188.

775 White, A.T., Courtney, C.A., Salamanca, A., 2002. Experience with marine protected area 776 planning and management in the Philippines. Coast. Manage. 30: 1-26.

777 Worm, B., 2017. Marine conservation: How to heal an ocean. Nature. 543: 630-631. 
Appendix A

Text A.1 Questionnaire administered to the 11 MPAs studied here

MPA Name:

Country: Date:

\section{General Information}

year of creation:

year of implementation:

number of highest protected zone:

total highest protected zone size (ha):

size of each highest protected zone (ha): 1 . $; 2$. ;3. ;4. total zones number:

\section{Legal status and authority of the management body}

pre-existence of the management body before the creation of the MPA: $\square$ yes, $\square$ no nature of the management body: $\square$ public, $\square$ private, $\square$ mixed

the management body was constituted by institution/s having the legal power to issue penalties to offenders: $\square$ yes, $\square$ no

the management body has the legal authority to directly employ the manager and the staff: only the manager, $\square$ both the manager and the staff, $\square$ neither of the two the management body directly allocates its own police officers for surveillance (when it is the case): $\square$ yes, $\square$ no

802 MPA staff members have the legal power to issue penalties to offenders: $\square$ yes, $\square$ no

\section{Structure}

level of centralization: $\square$ national, $\square$ regional, $\square$ local

which are the hierarchical levels in the management of the MPA?

total Employee Number:

permanent Employee Number:

non-Permanent Employee Number:

full-Time Employee Number:

part-Time Employee Number:

all Year Employee Number:

seasonal Employee Number:

(months of employment of the seasonal employees:

managers Number:

operative Employee number: 
administrative Employee number:

number of managers appointed since the implementation of the MPA: type of contract of the manager: $\square$ permanent position, $\square$ no-permanent position duration of the employment of the current manager number of months: educational level of the manager: $\square \mathrm{PhD} ; \square \mathrm{MD}, \square \mathrm{BD}, \square$ High School, $\square$ Inferior level, degree focus consistent with natural resource management issues: $\square$ yes, $\square$ no specific training in marine subjects after the graduation: $\square$ yes, $\square$ no previous employment on environmental or marine sector: $\square$ yes, $\square$ no previous employment in other MPAs: $\square$ yes, $\square$ no specific training in management: $\square$ yes, $\square$ no previous management experience, e.g. in companies: $\square$ yes, $\square$ no

\section{Networking}

presence of a police body responsible for enforcing the MPA: $\square$ yes, $\square$ no, $\square$ the 'police' function is provided by MPA staff active collaboration (e.g. working together in the field, sharing funds) between MPA management body and police body: $\square$ yes, $\square$ no surveillance data available, in terms of 'hours' carried out by the police body: $\square$ yes, $\square$ no

\section{Management performance}

Type of mission

$\square$ conservation, $\square$ education, $\square$ monitoring and research, $\square$ recreation, $\square$ resources management, $\square$ other:

\section{Culture and Goals}

presence of a stated mission in one or more official documents: $\square$ formalized, $\square$ not formalized presence of a stated vision in one or more official documents: $\square$ formalized, $\square$ not formalized technically correct statement of the vision: $\square$ inaccurate, $\square$ accurate presence of a stated goals in one or more official documents: $\square$ formalized, $\square$ not formalized goals formalized in documents currently in effect: $\square$ not updated, $\square$ updated percentage of measurable goals: $\square 0, \square 1-25 \%, \square 26-50 \%, \square 51-75 \%, \square 76-100 \%$

\section{Environmental education}

duration (number of years) of environmental education projects: $\square$ none, $\square$ occasionally, $\square$ 2-5 years consecutively, $\square$ 6-9 years consecutively, $\square$ more than 9 years consecutively classes of stakeholders involved in environmental education projects: $\square$ students, $\square$ local community, $\square$ tourists, $\square$ local authorities, $\square$ others: number of people involved in environmental education projects in 2014: effectiveness of environmental education projects: $\square$ no or data non available, $\square 1-25 \%$, $\square$ 26$50 \%, \square 51-75 \%, \square 76-100 \%$ 


\section{Enforcement}

kind of enforcement adopted by the MPA staff: $\square$ none, $\square$ interpretative enforcement, $\square$ legal enforcement networking (cooperation) with police bodies: $\square$ yes, $\square$ no methods employed by the MPA for the surveillance: $\square$ at sea, $\square$ from land, $\square$ daytime, $\square$ night time, $\square$ video cameras, $\square$ radar, $\square$ vessel monitoring system, $\square$ night vision binocular, $\square$ camera with georeferenced position, $\square$ laser hours spent by the MPA staff for the surveillance per year: hours spent by the police bodies for the surveillance per year : amount of hours the MPA staff spend for the surveillance each month during the winter (October to May):

amount of hours the MPA staff spend for the surveillance each month during the winter (June to September):

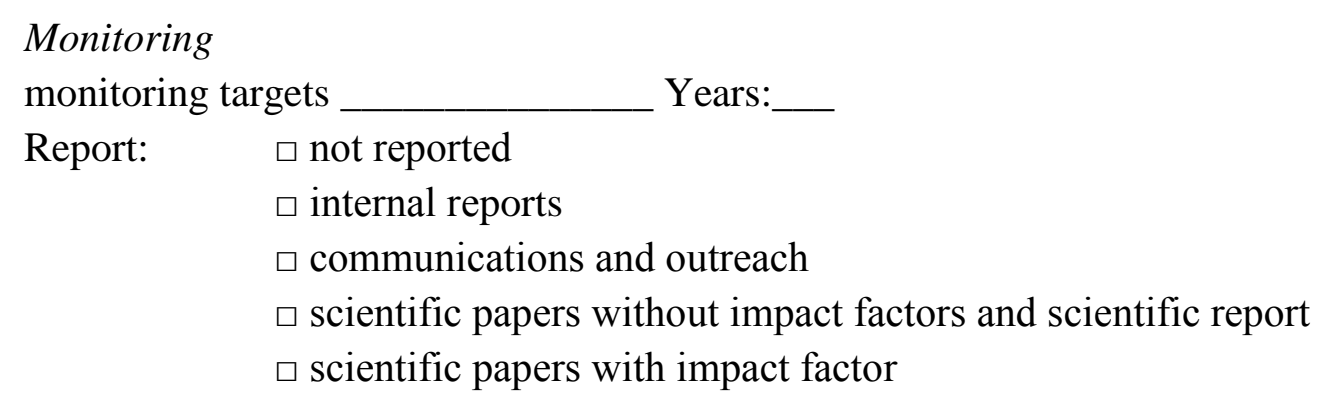


monitoring targets

Report: $\quad \square$ not reported

$\square$ internal reports

$\square$ communications and outreach

$\square$ scientific papers without impact factors and scientific report

$\square$ scientific papers with impact factor

\section{Management data}

presence of records of the surveillance activities by the MPA staff: $\square$ yes, $\square$ no

data availability about the hours spent for the surveillance by the MPA staff: $\square$ data not available, $\square$ data approximated, $\square$ data available

data availability about the number of people involved in environmental education projects:

data not available, $\square$ data approximated, $\square$ data available

existence of an evaluation process of the effectiveness of the environmental education projects:

yes, $\square$ no

availability of the data about the effectiveness of the environmental education project: $\square$ data not available, $\square$ data approximated, $\square$ data available 
4920 Text A.2 List of the monitoring targets considered in the monitoring index

$921 \quad$ State

8922 Benthic assemblage

9923 Carlit

10924 Coralligenous

11925

Corallum rubrum

Entozoan

Epinephelus marginatus

Fish assemblage

Gorgonians

Maps habitat

Mammals and turtles

Octopus vulgaris

Palinurus elephas

Patella ferruginea

Pinna nobilis

Posidonia oceanica

Scyllarides latus

Sea birds

Sea urchins

Water (abiotic factors)

Zooplancton

\section{Threats/Pressure}

Artisanal fisheries

Artisanal fisheries through logbook

Boating

Diving

Invasive species

Recreational fisheries

Recreational fisheries through logbook

Touristic activities (other than the previous) 
Table A.1 Strucuture of the Culture and Goals Index (CGI)

\begin{tabular}{|c|c|c|c|}
\hline Items & Weight & Categories and values & Scores=Ranks \\
\hline \multirow[b]{2}{*}{$\begin{array}{l}\text { presence of a stated } \\
\text { mission in one or more } \\
\text { official documents }\end{array}$} & \multirow{2}{*}{$\begin{array}{l}\text { A weight of } 2 \text { has been assigned to this item in } \\
\text { order to highlight the importance of having a } \\
\text { formalized mission as a guide for goals } \\
\text { statement and strategy planning }\end{array}$} & not formalized $=0$ & \multirow{15}{*}{$1-8$} \\
\hline & & formalized $=1$ & \\
\hline \multirow{2}{*}{$\begin{array}{l}\text { presence of a stated vision } \\
\text { in one or more official } \\
\text { documents }\end{array}$} & & not formalized $=0$ & \\
\hline & & formalized $=1$ & \\
\hline \multirow{2}{*}{$\begin{array}{l}\text { technically correct } \\
\text { statement of the vision }\end{array}$} & & inaccurate $=0$ & \\
\hline & & accurate $=1$ & \\
\hline \multirow{2}{*}{$\begin{array}{l}\text { presence of stated goals in } \\
\text { one or more official } \\
\text { documents }\end{array}$} & & not formalized $=0$ & \\
\hline & & formalized $=1$ & \\
\hline \multirow{2}{*}{$\begin{array}{l}\text { goals formalized in } \\
\text { documents currently in } \\
\text { effect }\end{array}$} & & not updated $=0$ & \\
\hline & & updated $=1$ & \\
\hline \multirow{5}{*}{$\begin{array}{l}\text { percentage of measurable } \\
\text { goals, calculated as the } \\
\text { number of measurable } \\
\text { goals respect to the total } \\
\text { number of goals } \\
\text { formalized }\end{array}$} & & $0 \%=0$ & \\
\hline & & $1-25 \%=0.5$ & \\
\hline & & $26-50 \%=1$ & \\
\hline & & $51-75 \%=1.5$ & \\
\hline & & $75-100 \%=2$ & \\
\hline
\end{tabular}

Table A.2 Structure of the Environmental Education Index (EEI)

959 EEI is constituted by four items

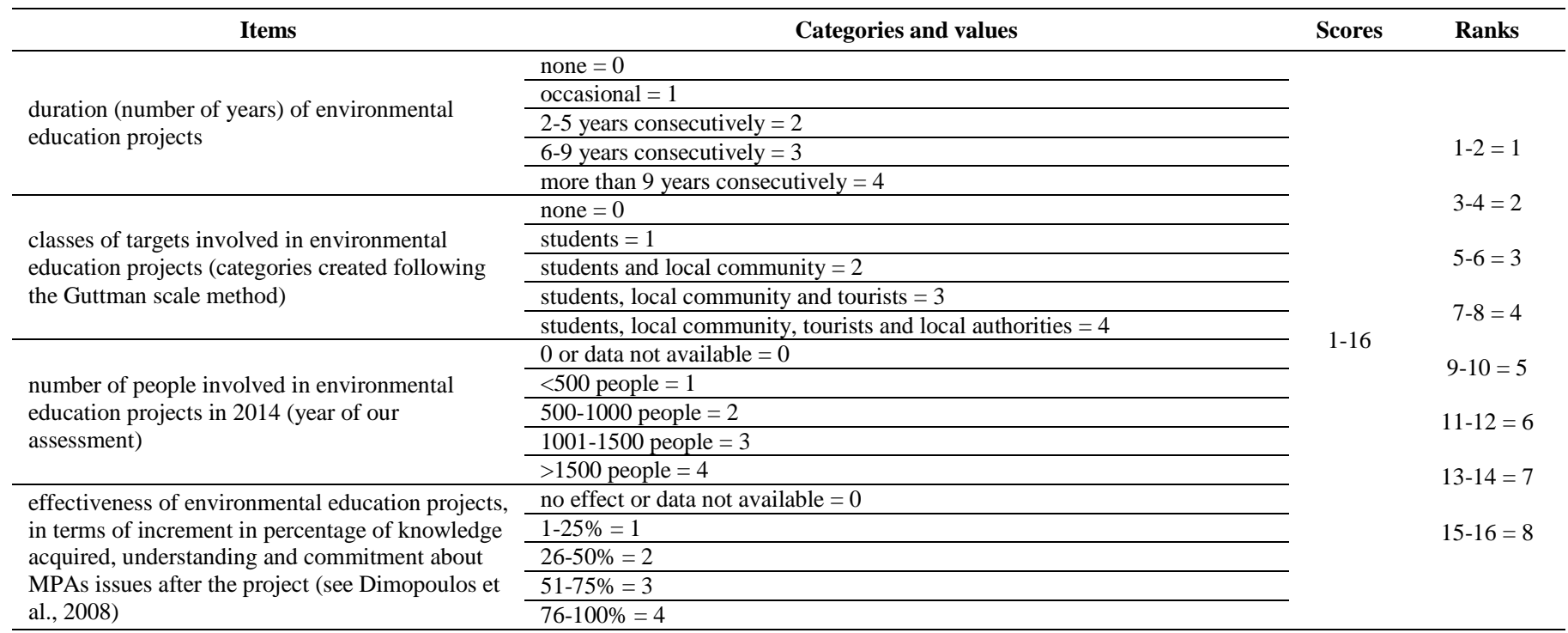




\section{Table A.3 Structure of the Enforcement Index (EI)}

EI is constituted by six items, with two of them taking into account the MPA surface area. In order to assess these two items that are dependent on the MPA surface area, we attributed a score to each MPA on the basis of their total surface area (Table 1 in the manuscript).

\begin{tabular}{|c|c|c|c|c|}
\hline Items & Weight & Categories and values & Scores & Ranks \\
\hline \multirow{3}{*}{$\begin{array}{l}\text { kind of enforcement adopted } \\
\text { by the MPA staff }\end{array}$} & & none $=0$ & \multirow{34}{*}{$1-24$} & \\
\hline & & interpretative enforcement $=1$ & & \\
\hline & & legal enforcement $=2$ & & \\
\hline \multirow{2}{*}{$\begin{array}{l}\text { networking (cooperation) } \\
\text { with police bodies }\end{array}$} & & no $=0$ & & \\
\hline & & yes $=1$ & & \\
\hline $\begin{array}{l}\text { methods employed by the } \\
\text { MPA for the surveillance }\end{array}$ & & $\begin{array}{l}\text { a score of } 0.1 \text { for each method } \\
\text { employed: at sea/from land/daytime/ } \\
\text { at night/video camera/radar/vessel } \\
\text { monitoring system/night vision } \\
\text { binocular/camera with georeferenced } \\
\text { position/laser }\end{array}$ & & \\
\hline \multirow{9}{*}{$\begin{array}{l}\text { hours spent by the MPA staff } \\
\text { for the surveillance per year } \\
\text { divided by the surface MPA } \\
\text { score (the nine categories } \\
\text { have been created } \text { a posteriori } \\
\text { in order to assign to the ratio } \\
\text { a value) }\end{array}$} & \multirow{9}{*}{$\begin{array}{l}\text { a weight of } 1.5 \text { has been assigned to the hours of } \\
\text { surveillance carried out by MPAs staff that has } \\
\text { the authority to inflict penalties or when staff } \\
\text { members work jointly with a police body that has } \\
\text { the authority to do it }\end{array}$} & zero hours $=0$ & & \\
\hline & & $1-100$ hours $=1$ & & \\
\hline & & $101-200$ hours $=2$ & & \\
\hline & & $201-300$ hours $=3$ & & $1-3=1$ \\
\hline & & $301-400$ hours $=4$ & & \\
\hline & & $401-500$ hours $=5$ & & $4-6=2$ \\
\hline & & $501-600$ hours $=6$ & & \\
\hline & & $601-700$ hours $=7$ & & $7-9=3$ \\
\hline & & $>700$ hours $=8$ & & \\
\hline \multirow{9}{*}{$\begin{array}{l}\text { hours spent by the police } \\
\text { bodies for the surveillance per } \\
\text { year divided by the surface } \\
\text { MPA score (the nine } \\
\text { categories have been created } \\
\text { a posteriori in order to assign } \\
\text { to the ratio a value) }\end{array}$} & \multirow{9}{*}{$\begin{array}{l}\text { A weight of } 1.2 \text { has been assigned to the hours of } \\
\text { surveillance performed by police bodies, which } \\
\text { have the duty to insure safety rules at sea beside } \\
\text { the MPA surveillance. This weight is } \\
\text { intermediate between the one assigned to the } \\
\text { hours of surveillance performed by MPA staff } \\
\text { members (when do not have any legal authority) } \\
\text { and the one assigned to the hours of surveillance } \\
\text { performed by staff members having the legal } \\
\text { power and that have the only surveillance task } \\
\text { inside the MPA }\end{array}$} & zero hours $=0$ & & $10-12=4$ \\
\hline & & $1-35$ hours $=1$ & & \\
\hline & & $36-70$ hours $=2$ & & $13-15=5$ \\
\hline & & $71-105$ hours $=3$ & & \\
\hline & & $106-140$ hours $=4$ & & $16-18=6$ \\
\hline & & $141-175$ hours $=5$ & & \\
\hline & & $176-210$ hours $=6$ & & $19-21=7$ \\
\hline & & $211-245$ hours $=7$ & & $22-24=8$ \\
\hline & & $>245$ hours $=8$ & & \\
\hline \multirow{4}{*}{$\begin{array}{l}\text { amount of hours the MPA } \\
\text { staff spend for the } \\
\text { surveillance each month } \\
\text { during the winter (October to } \\
\text { May) divided by the surface } \\
\text { MPA score }\end{array}$} & & zero hours $=0$ & & \\
\hline & & $1-40$ hours $=1$ & & \\
\hline & & $41-80$ hours $=2$ & & \\
\hline & & $81-160$ hours $=3$ & & \\
\hline \multirow{6}{*}{$\begin{array}{l}\text { percent increase of the hours } \\
\text { of surveillance from winter to } \\
\text { summer }\end{array}$} & & no increment $=0$ & & \\
\hline & & $1-100 \%$ increment $=0.2$ & & \\
\hline & & $100-200 \%=0.4$ & & \\
\hline & & $200-300 \%=0.6$ & & \\
\hline & & $300-400 \%=0.8$ & & \\
\hline & & $>400$ increment $=1$ & & \\
\hline
\end{tabular}




\section{Table A.4 Structure of the Monitoring Index (MI)}

969

970

MI was designated in order to assess the effort deployed in the monitoring of the state of the system (in our case the MPA) and the pressures, or threats (Borja et al., 2012), acting upon it. For both state and pressures, we considered several monitoring targets, selected on the basis of the monitoring targets actually surveyed by the MPAs considered here. In total, 20 monitoring targets have been taken into account for the assessment of the state (e.g. fish assemblages, sea urchins, Posidonia oceanica meadows, Patella ferruginea, Pinna nobilis and other protected habitats and species of the Mediterranean Sea) (Bianchi, 2002; Bianchi \& Morri, 2003; Boudouresque \& Bianchi, 2013; Rovere et al., 2011), and 8 for the assessment of the pressures (e.g. effort of artisanal fishery, invasive species, recreational activities), for a grand total of 28 monitoring targets.

\begin{tabular}{|c|c|c|c|}
\hline Items & Categories and values & Scores & Ranks \\
\hline \multirow{5}{*}{$\begin{array}{l}\text { duration (number of years) of } \\
\text { monitoring }\end{array}$} & none $=0$ & \multirow{10}{*}{$1-224$} & $1-28=1$ \\
\hline & occasional $=1$ & & \\
\hline & $\begin{array}{l}\text { sampling activities carried out for } 2-4 \text { years consecutively or samplings } \\
\text { carried out every } 3-5 \text { years for } \max 3 \text { times }=2\end{array}$ & & $29-56=2$ \\
\hline & $\begin{array}{l}\text { sampling carried out for 5-7 years consecutively or every 3-5 years for } \\
3-5 \text { times }=3\end{array}$ & & $57-84=3$ \\
\hline & $\begin{array}{l}\text { sampling carried out for more than } 7 \text { years consecutively or every 3-5 } \\
\text { years more than } 6 \text { times }=4\end{array}$ & & $85-112=4$ \\
\hline \multirow{5}{*}{ methods to report monitoring data } & not reported $=0$ & & $113-140=5$ \\
\hline & internal reports $=1$ & & \\
\hline & communications and outreach $=2$ & & $141-168=6$ \\
\hline & scientific papers without impact factors and scientific reports $=3$ & & $169-196=7$ \\
\hline & scientific papers with impact factors $=4$ & & $197-224=8$ \\
\hline
\end{tabular}

\section{Table A.5 Structure of the Management Data Index (MDI)}

979 MDI assesses the effort deployed in the collection of management data useful for improvement of the strategy and 980 the activities. It is constituted by 5 items.

\begin{tabular}{|c|c|c|c|}
\hline Items & Weight & Categories and values & Scores=Ranks \\
\hline \multirow{2}{*}{$\begin{array}{l}\text { records of the surveillance activities by } \\
\text { the MPA staff }\end{array}$} & \multirow{2}{*}{$\begin{array}{l}\text { a weight of } 2 \text { has been assigned to this item to } \\
\text { highlight the importance of keeping records of the } \\
\text { surveillance activities }\end{array}$} & no $=0$ & \multirow{12}{*}{$1-8$} \\
\hline & & yes $=1$ & \\
\hline \multirow{3}{*}{$\begin{array}{l}\text { data availability about the hours spent for } \\
\text { the surveillance by the MPA staff }\end{array}$} & & data not available $=0$ & \\
\hline & & approximate data $=1$ & \\
\hline & & precise data $=2$ & \\
\hline \multirow{3}{*}{$\begin{array}{l}\text { data availability about the number of } \\
\text { people involved in environmental } \\
\text { education projects }\end{array}$} & & data not available $=0$ & \\
\hline & & approximate data $=1$ & \\
\hline & & precise data $=2$ & \\
\hline \multirow{2}{*}{$\begin{array}{l}\text { evaluation process of the effectiveness of } \\
\text { the environmental education projects }\end{array}$} & & no $=0$ & \\
\hline & & yes $=1$ & \\
\hline \multirow{2}{*}{$\begin{array}{l}\text { availability of the data about the } \\
\text { effectiveness of environmental education } \\
\text { projects }\end{array}$} & & no $=0$ & \\
\hline & & yes $=1$ & \\
\hline
\end{tabular}

\section{Text A.3 References in the appendix}

984 marine ecosystem quality. Ecol. Indic. 12: 1-7. 
Bianchi, C.N., 2002. Il monitoraggio della biodiversità nelle Aree Marine Protette: considerazioni scientifiche e metodologiche. Notiziario della Società Italiana di Biologia Marina. 41: 89-95.

Bianchi, C.N., Morri, C., 2003. Importanza della fauna bentonica per il monitoraggio della biodiversità nelle Aree Marine Protette. In: Le Aree Marine Protette del Mediterraneo, eds. Carrada, G.C., Coiro, P., Russo, G.F., Centro Studi Tegea, Electa, Napoli; pp. 125-134.

Boudouresque, C.F., Bianchi, C.N., 2013. Une idée neuve: la protection des espèces marines. In: GIS Posidonie: plus de 30 ans au service de la protection et de la gestion du milieu marin, eds. Le Diréach, L., Boudouresque, C.F., GIS Posidonie, Marseille. pp 85-91.

993 Rovere, A., Parravicini, V., Firpo, M., Morri, C., Bianchi C.N., 2011. Combining geomorphologic, biological and 994 accessibility values for marine natural heritage evaluation and conservation. Aquat. Conserv. 21: 541-552. 